\title{
EDITORIAL
}

\section{Pulmonary hypertension at exercise in COPD: does it matter?}

\author{
Robert Naeije* and Bart G. Boerrigter ${ }^{\#}$
}

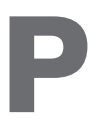
ulmonary hypertension is a common complication of chronic obstructive pulmonary disease (COPD). In these patients, the increase in pulmonary artery pressure (PAP) is usually mild, in the range of 20 to $30 \mathrm{mmHg}$ mean PAP (mPAP) with little progression over the years, on average $0.4 \mathrm{mmHg}$ per year, and is preventable and sometimes partially reversible with chronic oxygen therapy $[1,2]$. Sharp increases in PAP may occur during sleep or episodes of acute respiratory failure, and also during exercise $[1,2]$. Pulmonary hypertension in COPD is explained by the combined effects of hypoxia, inflammation, hyper-inflation of the lungs and an increase in left ventricular end-diastolic pressure $[2,3]$. Increased PAP is associated with decreased survival, may be the cause of clinical right heart failure, particularly in hypoxaemic patients with associated salt and water retention, and is thought to limit exercise capacity [1, 2].

Right heart catheterisations to evaluate the pulmonary circulation used to be common practice in patients with advanced COPD. The procedure is nowadays limited to the work-up of lung transplantation or lung volume reduction surgery, or for the understanding of symptoms that appear out of proportion with the lung function impairment $[2,4]$. Some rare patients with COPD, approximately $1 \%$ of those referred to expert centres, present with "out of proportion pulmonary hypertension". This entity is defined by a particular combination of mPAP $>35-40 \mathrm{mmHg}$, only moderate airflow obstruction, hypoxaemia and hypocapnia [2-5]. Whether "out of proportion pulmonary hypertension" actually represents a form of pulmonary arterial hypertension (PAH) triggered by altered blood gases or inflammation associated with COPD remains unclear [5]. But there has been no reported evidence until now that targeted therapies shown effective in the treatment of PAH might be of any help.

In this context of relative disenchantment, HILDE et al. [6] report in this issue of the European Respiratory Journal an interesting paper on invasive exercise haemodynamics in COPD. The authors catheterised 98 COPD patients with Global Initiative for Chronic Obstructive Lung Disease (GOLD) stage II to IV

*Depts of Pathophysiology and Cardiology, Erasme Academic Hospital, Free University of Brussels, Brussels, Belgium. "Dept of Pulmonary Diseases, VU University Medical Center, Amsterdam, The Netherlands.

CORRESPONDENCE: R. Naeije, Dept of Physiology, Erasme Campus CP 604, 808 Lennik Road, B1070 Brussels, Belgium. E-mail: rnaeije@ulb.ac.be disease severity. Pulmonary hypertension defined by a mPAP higher than $25 \mathrm{mmHg}$ was identified at rest in $27 \%$ of the patients, increasing to approximately half of those in GOLD stage IV. This is in keeping with previous reports of increased PAP in proportion to COPD severity [1,2]. More original was the evaluation of the functional state of the pulmonary circulation by multipoint PAP-cardiac output or PAP-workload relationships up to maximum aerobic exercise capacity (or maximum oxygen uptake, $\left.\mathrm{VO}_{2} \max \right)$. As recently discussed, this approach allows for a refined measurement of the resistive properties of the pulmonary circulation, and may help understanding of the mechanisms of decreased exercise capacity [7]. Exercise was associated with a slight increase in pulmonary vascular resistance (PVR), in contrast with the decrease normally seen in healthy subjects. The slope of mPAP-cardiac output was on average $4.5 \mathrm{mmHg} \cdot \mathrm{L}^{-1} \cdot \mathrm{min}^{-1}$ in the patients without resting pulmonary hypertension and $7.2 \mathrm{mmHg} \cdot \mathrm{L}^{-1} \cdot \mathrm{min}^{-1}$ in the patients with resting pulmonary hypertension, which is higher than in normal subjects in whom the slope of $\mathrm{mPAP}$-cardiac output does not normally exceed $3 \mathrm{mmHg} \cdot \mathrm{L}^{-1} \cdot \mathrm{min}^{-1}$ [7-9]. A slope of $3 \mathrm{mmHg} \cdot \mathrm{L}^{-1} \cdot \mathrm{min}^{-1}$ corresponds to a $\mathrm{mPAP}$ around $30 \mathrm{mmHg}$ at a cardiac output of $10 \mathrm{~L} \cdot \mathrm{min}^{-1}$, which is close to the former definition of exercise-induced pulmonary hypertension by a mPAP $>30 \mathrm{mmHg}$ at exercise which was abandoned at the 2008 Dana Point world congress on pulmonary hypertension [10]. Thus Hilde et al. [6] show that "exercise-induced pulmonary hypertension" is common in COPD. This is an important finding. One would certainly agree with the authors that future definitions of pulmonary hypertension in COPD should rely on the slope of mPAP-cardiac output relationships.

HiLDE et al. [6] also expressed the pulmonary vascular response to exercise by mPAP-workload plots. This presentation also showed higher than normal slopes, as expected since there is a linear relationship between cardiac output, $V_{2}$ and workload [11]. However, cardiac output-workload relationships present with a marked inter-individual variability related to individual differences in mechanical efficiency of the work [8]. Therefore, it is preferable to define the functional state of the pulmonary circulation by mPAP-cardiac output rather than mPAPworkload plots, as it is flow and not workload that determines pulmonary vascular pressures.

HILDE $e$ al. [6] make a case that their exercise measurements were done in the supine position, and mention that this could be a limitation to their findings. This is true for the identification of exercise-induced changes in PVR. The upright 
position is associated with a decreased venous return and de-recruitment of pulmonary vessels, which increases resting PVR. However, low levels of exercise are associated with full recruitment of pulmonary vessels, so that subsequent fall in PVR at higher levels of exercise is entirely explained by the distensibility of the pulmonary resistive vessels, and body position does not affect the slope of mPAP-cardiac output relationships [12].

Many studies have reported on a higher than normal wedged PAP (PCWP) in COPD. In the National Emphysema Treatment Trial, $61 \%$ of the patients had a PCWP higher than the upper limit of normal of $12 \mathrm{mmHg}$ [13]. In the study of HiLDE et al. [6], PCWP was on average normal at rest, but increased markedly at exercise, in patients with, as well as without, pulmonary hypertension. It has been previously shown that in patients with COPD, PCWP and PAP increase at rest and more so at exercise, along with oesophageal pressures, in relation to dynamic hyperinflation and expiratory muscle contraction [14-16]. Therefore, pulmonary vascular pressures may actually increase with intrathoracic pressure becoming higher than reference atmospheric pressure, although a direct compression of the heart may also occur, thereby further increasing left ventricular end-diastolic pressure [14-16]. As illustrated in figure 1, intrathoracic pressure swings in patients with COPD may be huge, but are more positive than negative. Associated changes in PCWP are tightly related to left ventricular enddiastolic pressure [14] and are therefore not caused by a compression of pulmonary vessels by positive alveolar pressures. It is thus very likely that increased intrathoracic pressure at exercise contributed to increased slope of mPAPcardiac output in the patients reported by HILDE et al. [6].
Pulmonary vascular pressures used to be averaged over two to three respiratory cycles, rather than measured only at endexpiration as currently recommended [14-16]. In the study by HILDE et al. [6], pulmonary vascular pressures were measured at end-expiration and the authors even added a temporary breath-hold. Whether this manoeuvre might have further increased or decreased intrathoracic pressure, and thus $\mathrm{mPAP}$ and PCWP is unclear. However, the question remains as to whether it makes "physiological" sense to read PAP and PCWP exclusively at the moment when intrathoracic pressure is highest. It may be more sensible to subtract oesophageal pressures from pulmonary vascular pressures for a realistic evaluation of the pulmonary circulation in the presence of marked variations in intrathoracic pressures [14-16].

Another interesting aspect of the report by HiLDE et al. [6] was the abnormal behaviour of the pulmonary artery compliance (Ca), which decreased at exercise in COPD patients, in contrast with the expected increase in healthy subjects [17]. There is an obligatory hyperbolic inverse relationship between PVR and $\mathrm{Ca}$, with a constant value for PVR $\times \mathrm{Ca}$, or time constant of the pulmonary circulation persisting over a wide range of pulmonary vascular diseases and severities of pulmonary hypertension [18, 19]. Mildly increased PVR, such as for example in patients after successful pulmonary endarterectomy, may be a cause of markedly decreased Ca accounting for persistent exercise intolerance [20].

What is the clinical relevance of the findings reported by HILDE et al. [6]? Peak exercise PVR and Ca were negatively correlated to maximum workload or 6-min walk distance, which indirectly suggests that excessive afterloading of the right ventricle would limit exercise capacity. However, the patients
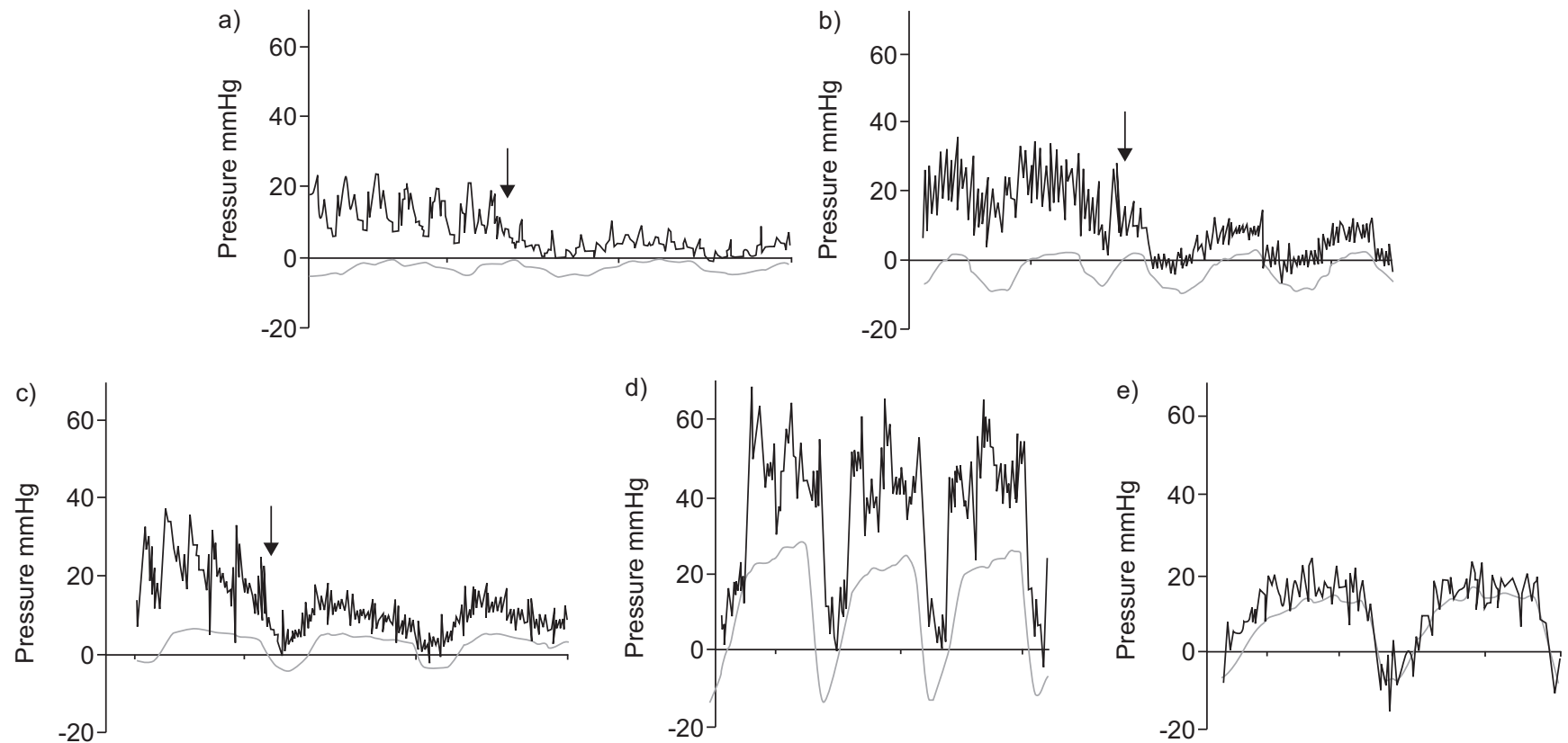

FIGURE 1. Simultaneous pressure recordings of pulmonary artery pressure (PAP) and pulmonary capillary wedge pressure (PCWP) (black lines) with oesophageal pressure (grey lines) in a) a healthy subject at rest and b) during exercise; and a chronic obstructive pulmonary disease (COPD) patient (forced expiratory volume in $1 \mathrm{~s} 30 \%$ of predicted) c) at rest, d) PAP during exercise and e) PWCP during exercise. The arrows represent the moment of balloon inflation. Note the large influence of intrathoracic pressure on PAP and PCWP, at rest and more so during exercise in COPD. (B.G. Boerrigter and A. Vonk-Noordegraaf; personal communication.) 
had also a marked ventilatory impairment, with increased arterial carbon dioxide tension and little or no ventilatory reserve. Pulmonary hypertension might not matter much when patients cannot increase their ventilation [21]. It may be that the right ventricle limits exercise capacity only in COPD patients with "out of proportion pulmonary hypertension", who present with preserved ventilatory reserve, hypocapnia hypoxaemia and very low mixed venous oxygenation at maximal exercise [22]. Only these patients might be candidates for trials of targeted therapies with drugs shown efficacious in PAH.

Right heart catheterisation at exercise in COPD requires a lot of skill, persistence, patience and persuasion. HILDE et al. [6] are to be commended for this "tour de force" on almost a hundred patients. Their results contribute to the understanding of the pulmonary circulation in COPD and remind us of the importance of physiologically sound measurements. Further progress will require more insight into heart-lung interactions and right ventricular function as potential limiting factors of exercise capacity, for the identification of the subset of patients who might potentially benefit from therapies targeting the pulmonary circulation.

\section{STATEMENT OF INTEREST}

Conflict of interest information can be found alongside the online version of this article at www.erj.ersjournals.com

\section{REFERENCES}

1 Weitzenblum. Chronic cor pulmonale. Heart 2003; 89: 225-230.

2 Chaouat A, Naeije R, Weitzenblum E. Pulmonary hypertension in COPD. Eur Respir J 2008; 32: 1371-1385.

3 Peinado VI, Pizarro S, Barbera JA. Pulmonary vascular involvement in COPD. Chest 2008; 134: 808-814.

4 Hoeper MM, Barberà JA, Channick RN, et al. Diagnosis, assessment, and treatment of non-pulmonary arterial hypertension pulmonary hypertension. J Am Coll Cardiol 2009; 54: S85-S96.

5 Chaouat A, Bugnet AS, Kadaoui N, et al. Severe pulmonary hypertension and chronic obstructive pulmonary disease. Am J Respir Crit Care Med 2005; 172: 189-194.

6 Hilde JM, Skjørten I, Hansteen V, et al. Haemodynamic responses to exercise in patients with COPD. Eur Respir J 2013; 41: 1031-1041.

7 Saggar R, Lewis GD, Systrom DM, et al. Pulmonary vascular response to exercise: a haemodynamic observation. Eur Respir J 2012; 39: 231-234.
8 Argiento $\mathrm{P}$, Vanderpool RR, Mulè $\mathrm{M}$, et al. Exercise stress echocardiography of the pulmonary circulation: limits of normal and sex differences. Chest 2012; 142: 1158-1165.

9 Lewis GD. Pulmonary vascular response patterns to exercise: is there a role for pulmonary arterial pressure assessment during exercise in the post Dana Point area? Adv Pulm Hypertens 2010; 9: 92-100.

10 Galiè N, Hoeper MM, Humbert M, et al. Task Force for Diagnosis and Treatment of Pulmonary Hypertension of European Society of Cardiology (ESC), European Respiratory Society (ERS), International Society of Heart and Lung Transplantation (ISHLT). Guidelines for the diagnosis and treatment of pulmonary hypertension. Eur Respir J 2009; 34: 1219-1263.

11 Guyton AC, Hall JE. Textbook of Medical Physiology. 12th Edn. St. Louis, Saunders, 2011.

12 Reeves JT, Dempsey JA, Grover RF. Pulmonary circulation during exercise. In: Weir EK, Reeves JT, eds. Pulmonary Vascular Physiology and Physiopathology. New York, Marcel Dekker, 1989; pp. 107-133.

13 Scharf SM, Iqbal M, Keller C, et al. Hemodynamic characterization of patients with severe emphysema. Am J Respir Crit Care Med 2002; 166: 314-322.

14 Lockhart A, Tzareva M, Nader F, et al. Elevated pulmonary artery wedge pressure at rest and during exercise in chronic bronchitis: fact or fancy. Clin Sci 1969; 37: 503-517.

15 Rice DL, Awe RJ, Gaasch WH, et al. Wedge pressure measurement in obstructive pulmonary disease. Chest 1974; 66: 628-632.

16 Butler J, Schrijen F, Henriquez A, et al. Cause of the raised wedge pressure on exercise in chronic obstructive pulmonary disease. Am Rev Respir Dis 1988; 138: 350-354.

17 Slife DM, Latham RD, Sipkema $\mathrm{P}$, et al. Pulmonary arterial compliance at rest and exercise in normal humans. Am J Physiol 1990; 258: H1823-H1828.

18 Lankhaar JW, Westerhof N, Faes TJ, et al. Quantification of right ventricular afterload in patients with and without pulmonary hypertension. Am J Physiol Heart Circ Physiol 2006; 291: H1731-H1737.

19 Saouti N, Westerhof N, Postmus PE, et al. The arterial load in pulmonary hypertension. Eur Respir Rev 2010; 19: 197-203.

20 Bonderman D, Martischnig AM, Vonbank K, et al. Reduced exercise capacity after successful pulmonary endarterectomy is due to decreased pulmonary arterial compliance. Chest 2011; 139: 122-127.

21 Pynnaert C, Lamotte M, Naeije R. Aerobic exercise capacity in COPD patients with and without pulmonary hypertension. Respir Med 2010; 104: 121-126.

22 Boerrigter BG, Bogaard HJ, Trip $\mathrm{P}$, et al. Ventilatory and cardiocirculatory exercise profiles in COPD: the role of pulmonary hypertension. Chest 2012; 142: 1166-1174. 